\title{
Heterogeneity of social anxiety in treatment-seeking adults who stutter: A latent profile
}

\section{analysis}

Tomosumi Haitani ${ }^{a^{*}}$, Naomi Sakai ${ }^{\text {a }}$, Koichi Mori ${ }^{b}$, Tomohito Houjou ${ }^{c}$

${ }^{\text {a }}$ Department of Rehabilitation for Sensory Functions, Research Institute, National Rehabilitation Center for Persons with Disabilities (NRCD)

${ }^{\mathrm{b}} \mathrm{NRCD}$.

${ }^{\mathrm{c}}$ Hospital, NRCD.

*Corresponding author: Tomosumi Haitani highj118@gmail.com

\section{Acknowledgments}

We are grateful to the adults who stuttered and answered the LSAS in the present study. We are also thankful to Yoshimasa Sakata, a speech therapist who collected the data used in the present study. Additionally, the authors would like to thank Editage (www.editage.com) for the English language review.

This work was supported by JSPS KAKENHI Grant Number JP21K17542.

\section{Declaration of conflicting interest}

The authors have no declarations of conflicting interest to report. 


\begin{abstract}
Purpose: Adults who stutter (AWS) often experience social anxiety. Social anxiety is explained by several situational factors, one of which is a factor for telephone, which is unique to AWS. This unique social anxiety, which has not been observed in individuals with social anxiety disorder (SAD), may lead to heterogeneity or distinct subtypes of AWS. The present study aimed to investigate the heterogeneity of social anxiety in AWS in terms of feared social situations.
\end{abstract} Methods: Social anxiety was measured using the fear/anxiety scale of the Liebowitz Social Anxiety Scale (LSAS). The scores of the five subscales in the LSAS in 562 AWS were analyzed using latent profile analysis. First, the number of latent classes (subtypes) was determined through statistical criteria and interpretability. Next, the profiles of social anxiety, demographic data, communication attitudes, and the overall severity of social anxiety of the subtypes were investigated.

Results: Five latent class solutions led to good classifications. About one-quarter of AWS (156) were included in a subtype with sub-clinical levels of overall severity of social anxiety but severe social anxiety in telephone situations. Among them, 100 AWS showed severe social anxiety only in telephone situations. Psychosocial factors, including employment status and communication attitude, were related to extracted subtypes.

Conclusions: Some AWS have severe social anxiety specific to telephone situations, which is not proportional to the overall severity of social anxiety. The telephone-specific subtype of social anxiety has not been empirically extracted in principal diagnosis of SAD and can be unique in AWS. 
Keywords: Stuttering, Social anxiety, Subtype, Telephone, Latent profile analysis 


\section{Introduction}

\subsection{Stuttering and social anxiety}

People who stutter have often had aversive social experiences since childhood, including bullying, teasing, and negative reactions from others (Blood \& Blood, 2004, 2007, 2016; Langevin et al., 2009). These aversive social experiences could lead to social or psychological difficulties in adults who stutter (AWS) (Blood \& Blood, 2016; Iverach \& Rapee, 2014). One of these difficulties is social anxiety, which is highly prevalent among AWS (Craig \& Tran, 2014; Iverach et al., 2009; Menzies et al., 2008; Stein et al., 1996). When social anxiety increases, and impairs daily functioning, individuals with social anxiety can be diagnosed with social anxiety disorder (SAD) (American Psychiatric Association, 2013). It has been shown that the prevalence of SAD ranges from $18 \%$ to $60 \%$ among treatment-seeking AWS (Iverach et al., 2009; Menzies et al., 2008; Stein et al., 1996).

Although a meta-analysis showed that AWS have high social anxiety as a whole (Craig \& Tran, 2014), it has been shown that while some AWS have high social anxiety, some do not (Blood \& Blood, 2016; Ezrati-Vinacour \& Levin, 2004; Messenger et al., 2004). Furthermore, there seem to be individual differences in the levels of social anxiety depending on the situation, among AWS (Diehl et al., 2018; Menzies et al., 1999; Vanryckeghem et al., 2017). The present study focuses on individual differences or the heterogeneity of social anxiety in AWS. Individual differences or heterogeneity of the population can be represented by different subtypes (e.g., Nandi et al., 2009; Salzer et al., 2008). Next, we would review situational factors influencing social anxiety and subtypes of SAD, which can 
be related to each other.

\subsection{Situational factors influencing social anxiety and subtypes of SAD}

Previous studies have investigated situational factors for social anxiety (e.g., Cox et al., 2008;

Oakman et al., 2003; Safren et al., 1999; Stein et al., 2010). Several correlated factors, including the factors for public speaking, social interaction, and observation by others, have been identified in individuals with SAD (Oakman et al., 2003; Safren et al., 1999) and general populations (Cox et al., 2008; Stein et al., 2010).

Based on the feared social situations, the categorical solutions for SAD, which assume distinct subtypes exist among individuals with SAD, were suggested in the Diagnostic and Statistical Manual of Mental Disorders-IV (DSM-IV; American Psychiatric Association, 1994, 2000) and the DSM-5 (American Psychiatric Association, 2013), respectively. While the generalized subtype of SAD (individuals who fear most social situations) was specified in the DMS-IV ${ }^{1}$, performance-only subtype (individuals who fear only performance situations including speaking or performing in public) was specified in the DSM-5.

However, inconsistent with the categorical solution of the DSM, empirical studies have found that the generalized subtype can represent those with severe social anxiety (Aderka et al., 2012; Ruscio, 2010; Ruscio et al., 2008; Stein et al., 2000; Vriends et al., 2007) while the performance-only subtype

\footnotetext{
${ }^{1}$ Although generalized subtype of social phobia was introduced in the DSM-III-R for the first time in 1987, the term "social anxiety disorder" was not used at that time.
} 
can represent those with milder social anxiety (Boyers et al., 2017; Crome \& Baillie, 2014; Crome et al., 2015; Fuentes-Rodriguez et al., 2018; Peyre et al., 2016) on a continuum of severity. Furthermore, it has been shown that severe social anxiety in individuals with SAD is continuous with milder (subclinical) social anxiety in individuals without SAD (Kollman et al., 2006; Ruscio, 2010). These findings do not support the categorical solution but rather, support the dimensional solution, which assumes more severe levels of social anxiety, including those individuals with SAD, is continuous with milder levels on a single dimension.

It has also been found that social anxiety in various kinds of social situations could be explained by a single latent factor underlying overall severity of social anxiety (Crome \& Baillie, 2014; Gomez \& Watson, 2017; Knappe et al., 2011; Ruscio et al., 2008). In other words, several correlated situational factors can be substituted by a general factor for social anxiety. This unidimensional aspect of situational factors for social anxiety may be related to the failure to find distinct subtypes of SAD in terms of feared social situations (Boyers et al., 2017; Kollman et al., 2006).

In contrast, it has been shown that telephone situations can have specific and salient impacts on AWS (Diehl et al., 2018; James et al., 2009; James et al., 1999; Vanryckeghem et al., 2017) and anxiety in telephone situations cannot be explained well by the overall severity of social anxiety in AWS (submitted companion manuscript). Using the Liebowitz Social Anxiety Scale (LSAS), it was found the five situational factors influencing social anxiety in AWS, including the factors for eating, drinking, and party, telephone, observation or non-speech, interacting with strangers, and public 
speaking (submitted companion manuscript), and similar factors were also extracted in individuals with SAD except the factor for telephone (Safren et al., 1999; Stein et al., 2004). The factor for telephone was unique in AWS, whose factor score estimate was highest among the five. It was also shown that only $37 \%$ of the variance in the severity of anxiety in the telephone situations was explained by the fear/anxiety total score of the LSAS, while $60 \%$ to $76 \%$ in the other situations. It suggests that social anxiety in telephone situations is strongly influenced by the feature of telephone itself rather than the overall severity of social anxiety.

\subsection{Purpose}

This unique factor for telephones may lead to heterogeneity or distinct subtypes of AWS. The aim of the present study is to reveal the heterogeneity of social anxiety in AWS through several situational factors shown in Haitani et al., including telephone factors.

\section{Method}

\subsection{Participants}

The sample comprised 562 adults who visited the Hospital of the National Rehabilitation Center for Persons with Disabilities (NRCD) in Japan from August 2011 to December 2020 for their first medical examinations. They were (a) 18 years or older and (b) diagnosed with stuttering by a medical team including an otorhinolaryngologist and speech therapists. The LSAS was answered in a medical questionnaire and the data was analyzed retrospectively. Calculating the subscale scores led to the exclusion of one participant with all subscale scores missing (see section 2.2). Then, 561 
participants were included in the present study. The overall mean age was 29.03 years $(S D=9.06)$.

This sample included AWS reported in Haitani et al. (submitted). Available demographic data is shown in Table 1

\subsection{Measures}

\section{2-2-1. Liebowitz social anxiety scale}

We used the fear/anxiety scale of the Japanese self-report version of the LSAS adopted by

Chu et al. (2020). The respondents rated fear/anxiety in 24 social situations using a four-point Likerttype scale ranging from 0 to 3. 0-3 represent none, mild, moderate, and severe, respectively. The LSAS was part of the questionnaire for the first visit.

We used the following five subscales from the LSAS: They were subscale 1) eating, drinking, and party (consisting of items 3, 4, and 7); subscale 2) observation or non-speech (items 8 , 9, 13, 17, and 19); subscale 3) telephone (items 1 and 10); subscale 4) interaction with strangers (items 11 and 12); and subscale 5) public speaking (items 6, 15, 16, 20, and 23). These subscales have sufficient reliability (internal consistency) and factorial validity, and can constitute the multiple dimensions of the LSAS. Subscale scores were calculated by averaging item scores.

The subscales with any missing data were treated as scale-level missing data. When dealing with these data, including reporting means, $S D$ s, and correlations of the scale scores, full information maximum likelihood estimation (Revelle, 2018) was used.

To evaluate the overall severity of social anxiety through the fear/anxiety total score of the 
LSAS, we referred to Asakura et al. (2002), who showed the scores of the LSAS in Japanese individuals with severe, moderate, and mild symptoms of SAD, respectively.

2-2-2. Modified Erickson scale of communication attitudes (S-24) (Andrews \& Cutler, 1974; Sakai et al., 2014)

S-24 is a measure of communication attitudes of AWS. The 24 items representing communication attitudes, which can distinguish AWS and those who do not, were answered with 'yes' or 'no'. Half of the items were reversed, and the total score was analyzed. The total score ranged from 0 to 24 and a higher score indicates that AWS have more dysfunctional communication attitudes. The S-24 was used to explore communication attitudes of subtypes.

\subsection{Data analyses}

We used the statistical software R, version 4.0.5, for the analyses and adopted the missing at random (MAR) assumption (Enders, 2010).

We conducted latent profile analysis (LPA) to classify AWS based on the subscale scores of the LSAS (submitted companion manuscript). Confirming or exploring the factor structure of a scale can lead to refined indicators when investigating heterogeneity (Morin \& Marsh, 2015; Pastor et al., 2007).

LPA is a person-centered approach in which categorical latent classes explain individual differences, while factor analysis is a variable-centered approach, in which variables of a scale load on continuous latent factors. LPA assumes that the means of the observed indicators are different 
between the latent classes. LPA is a model-based method and has several advantages over traditional distance-based clustering methods, including $k$-means clustering and hierarchical clustering. First, LPA provides likelihood ratio tests and statistical fit indices to decide the number of classes, while distance-based clustering methods do not provide them, and subjective interpretation of a researcher often biases the decision of the number of classes. Second, LPA allows assessments of uncertainty of classification by calculating posterior probabilities of individuals belonging to each class, whereas distance-based clustering methods do not. Modal assignments are frequently used, where individuals are classified into classes to which they most likely belong. This assignment was also used in the present study. Other advantages can be seen in previous references (e.g., Vermunt \& Magidson, 2002).

Although there is no one fixed point of the required sample size for conducting LPA, more than 500 subjects would be necessary for statistical fit indices to work properly for deciding the number of classes (Nylund-Gibson \& Choi, 2018). Thus, 561 can be a sufficient sample size for detecting latent classes in the present study.

When conducting the LPA, we used Mplus Version 8 (Muthén \& Muthén, 1998-2017) and MplusAutomation package (Hallquist \& Wiley, 2018) in the statistical software R. We used maximum likelihood estimation with robust standard errors (MLR), which can handle missing data and scale chi-squared statistics accounting for the non-normal distribution of the data. In the LPA, the means and variances of the indicators in the latent classes were estimated. While the means of the 
indicators were assumed to vary across the classes, the variances were not (homogenous variance assumption). Covariance among the indicators were fixed at zero in the latent classes (local independence assumption). These constraints can lead to parsimony and stable model estimations (Vermunt \& Magidson, 2002). When estimating the models, different 500 sets of automatic starting values were randomly generated, and the solutions that led to the best likelihood were adopted.

\subsubsection{Determination of number of classes}

There is no simple method for determining the number of classes, and we referred to absolute model fit indices, relative fit indices, classification-based criteria, and substantive interpretability (Morgan et al., 2016; Nylund-Gibson \& Choi, 2018).

Absolute model fits were assessed using the log-likelihood value and the Lo-Mendell-Rubin adjusted Likelihood Ratio Test (LMR-aLRT; Lo et al., 2001). Log-likelihood is the basic quantity reflecting model fits, and a higher value (closer to 0) represents better fits. However, because a more complex model (with more classes) leads to a higher log-likelihood, it cannot be valid when determining the number of classes. LMR-aLRT compares the absolute fit of the model with $k-1$ classes and that with $k$ classes. The test provides the $p$ value used to evaluate the improvement of the fit by including one additional class. A smaller $p$ value (e.g., less than .05) indicates that an additional class leads to better fits of the model.

Relative fit indices were interpreted in relation to the other models. The Bayes Information Criteria (BIC; Schwarz, 1978) and the Consistent Akaike Information Criteria (CAIC; Bozdogan, 
1987) were used in the present study. They are calculated using the log-likelihood value, sample size, and the number of parameters estimated in the model. Lower values reflect better fit.

Classification-based criteria reflect how well a model classifies individuals into groups. The integrated classification likelihood BIC (ICL-BIC) was used in the present study, which is a combination of the BIC and posterior probability values. This was interpreted like BIC.

These likelihood ratio tests and information criteria can perform better with skewed distributions of the indicators than the other tests or criteria (Morgan et al., 2016). We examined the model fits with successively increasing numbers of latent classes, until model estimation error occurred or a class with few individuals (less than $5 \sim 8 \%$ of the sample; Nylund-Gibson \& Choi, 2018) was obtained. Substantial interpretability was attained by examining the profiles of social anxiety in each class.

\subsubsection{Confirming class separations}

After determining the number of classes, the average posterior probabilities in each class and entropy statistics were examined to evaluate the uncertainty of the classifications (NylundGibson \& Choi, 2018). The average posterior probability is the mean of posterior probabilities of the individuals belonging to each class, and a value greater than .70 reflected good assignments (NylundGibson \& Choi, 2018). The entropy statistic is calculated through the posterior probabilities, the overall sample size, and the number of classes, and it reflects the degree of the overall separation across the classes. The entropy statistic ranges from 0 to 1 , and a larger value reflects good 
separation. Although it is not possible to determine a single cut-off value of the entropy statistic (Wang et al., 2017), a value greater than .80 would be necessary when using the class memberships in subsequent analyses (Clark \& Muthén, 2013). Although the entropy statistic can decrease when the number of classes increases (Masyn, 2013), it is related to the correct number of classes (Tein et al., 2013; Wang et al., 2017). Thus, the entropy and related statistics (ICL-BIC) were also referred to when determining the number of classes in the present study.

\subsubsection{Investigations of the identified classes}

First, the subscale scores (indicators) of the identified classes were visualized. One-way analyses of variance (ANOVAs) were then conducted to investigate the group differences in the indicators. Then, pairwise comparisons were conducted using standardized mean differences (Hedges' $g)^{2}$. Sawilowsky (2009) provided rules of thumb for interpreting standardized mean differences: very small (0.01), small (0.2), medium (0.5), large (0.8), very large (1.2), and huge (2.0). Second, demographic data, including age, gender, and employment status, the S-24 and the fear/anxiety total scores were also compared between the classes. Chi-squared tests were conducted for categorical variables (gender and employment status) and one-way ANOVAs were conducted for the continuous variables (age, the S-24, and the fear/anxiety total score). Pairwise comparisons were also conducted when significant main effects were obtained in ANOVAs.

\subsection{Ethics}

2 These analyses were based on all available data. 
This research was approved by the institutional review board of the NRCD. The opt-out procedure was conducted from March to June 2021 on the website of the NRCD and in the hospital and research institute of the NRCD.

\section{Results}

The mean fear/anxiety total score was $30.47(S D=14.98)$. The total score of the 17 items used in the present study was highly correlated with the fear/anxiety total score $(r=.99)$.

\subsection{Determination of number of classes}

Table 1 shows the log-likelihood values, the results of the likelihood ratio tests, the values of the statistical information criteria, the values of the entropy statistic, and the minimum proportion of individuals belonging to the classes. Although the BIC, CAIC, and ICL-BIC indicate that the sevenclass solution is preferable, this solution led to a class that included only six percent of AWS.

Because classes with a few percentage of the sample would not be replicated (Nylund-Gibson \& Choi, 2018), we did not adopt this solution. We chose the five-class solution because LMR-aLRT suggests this solution might be preferable to the four-class solution and minimum proportion of individuals belonging to classes were greater than $10 \%$.

\subsection{Confirming class separations}

The average posterior probabilities $(.89, .85, .89, .79$, and .89 , ordered from class 1 to class 5) represented good assignments or separations. The profiles of social anxiety in the six classes suggest that separation has substantial meanings (see section 3.3). 


\subsection{Investigations of the identified classes}

The profiles of social anxiety in the six classes are shown in Figure 1. For a parsimonious understanding, we regarded mean scores greater than 2 as "severe" social anxiety, range from 1 to 2 as "moderate," and below 1 as "mild." Eighteen-five (15.2\%) of the AWS were included in class 1, which showed the mild social anxiety across all five kinds of the situations among the five classes. One-hundred and fifty-six $(27.8 \%)$ were in class 2 , which reported severe social anxiety in telephone situations. Among them, 100 participants (17.8\%) reported severe social anxiety only in telephone subscale. One-hundred and sixty $(28.5 \%)$ were in class 3 , which showed severe social anxiety in speech-related situations ${ }^{3}$, including telephone, interaction with strangers, and public speaking. Eighty-nine (15.9\%) were in class 4, which reported moderate social anxiety in speech-related situations. Seventy-one (12.7\%) were in class 5, which showed severe social anxiety across the social situations except for observation or non-speech situations.

One-way ANOVA revealed that all subscale scores were different between classes $(46.3 \leq$ $\left.F_{\mathrm{S}} \leq 530.5, .08 \leq \eta^{2} \mathrm{~s} \leq .49, p \mathrm{~s} \leq .001\right)$. Except for group 1 and 2 and group 3 and 4 in subscale 1 and 2, group 1 and 2 and group 3, 4, and 5 in subscale 3, and group 2 and 4 and group 3 and 5 in subscale 4, all the pairwise comparisons led to large standardized mean differences, greater than 0.8 .

\footnotetext{
3 Items in subscale 1 (eating, drinking, and party) in the present study also included potentially speech-related situations, such as "Drinking with others in public places." and "Going to a party." However, speech may have stronger influence on telephone situations, interacting with strangers, and public speaking situations than eating, drinking, and party situations for AWS. Thus, we used the term "speech-related situations".
} 
Descriptive statistics of the demographic data, the S-24, the fear/anxiety total score, and the

overall severity rating of social anxiety in the classes are shown in Table 3. Chi-squared test, excluding missing data, revealed that employment status was significantly associated with the class $\left(\chi^{2}=22.18, d f=8, p<.01\right)$. While the proportion of employed people was smallest, that of unemployed was largest in class 5 among the classes. The proportion of unemployed people was less in class 1 and 2. It was also found that the proportion of student was largest in class 3 . The association between gender and class also approached significance $\left(\chi^{2}=9.20, d f=4, p=.06\right)$ and the proportion of women was largest in class 3 and less in class 1 and 4.

Age and class were not significantly associated with each other $\left(F[1,559]=1.54, \eta^{2}=.003\right.$, $p=.22)$. The S-24 was significantly different between groups $\left(F[1,552]=147.4, \eta^{2}=.21, p\right.$ $<.001)^{4}$. Pairwise comparisons revealed that except for class 2 and $4(g=.14)$, all the comparisons were statistically significantly different with moderate or higher effects ( $g s \geq .54)$. The fear/anxiety total score was also significantly different between groups $\left(F[1,559]=789.9, \eta^{2}=.59, p<.001\right)$. Pairwise comparisons revealed that all the pairs were significantly different with large and higher effect sizes $(g s \geq .94)$.

\section{Discussions}

In the present study, we conducted the LPA to subtype treatment-seeking AWS based on social anxiety measured through the five subscales of the LSAS. The LPA led to good statistical

4 The data of the S-24 were missing in 7 participants. 
classification and substantive interpretability of six subtypes. These subtypes showed enough separation with standardized mean differences greater than approximately 0.8 in the subscales, corresponding to previous studies (Tein et al., 2013).

Seventy percent of the treatment-seeking AWS were included in the three distinct subtypes (class 2, 3, and 5) showing severe social anxiety in telephone situations. This means that severe anxiety in telephone situations is pervasive among treatment-seeking AWS, consistent with a previous study (Vanryckeghem et al., 2017). In particular, about one-quarter of AWS (156) were included in a subtype with severe social anxiety only in telephone situations and sub-clinical level of overall severity of social anxiety. Majority of them (100), about one-sixth of the sample, reported severe anxiety only in telephone situations. They might represent telephone-specific subtype of social anxiety, which has not been seen in individuals with a principal diagnosis of SAD.

This subtype appeared related to employment status; few unemployed people were included. It might indicate that they have to use telephone in job or job hunting, and have severe anxiety when using telephone. Previous studies have reported that using telephone at work bothers AWS (James et al., 1999; Klompas \& Ross, 2004). On the other hand, the S-24 score of this subtype was not significantly different from that of the class 4 (AWS with moderate speech-related social anxiety) and comparable to Japanese AWS who did not necessarily seek treatments (Sakai et al., 2017). They may not need treatments for general social anxiety and communication attitudes but telephonespecific treatments. 
The subtypes other than the subtype with potentially telephone-specific social anxiety are described below. Class 1 (15.2\% of the sample) showed mild social anxiety in all five kinds of social situations and the severe level of the fear/anxiety total score. This subtype was also characterized by lower unemployment rate and lower S-24 score; they can show better social functioning.

Class 3 (28.5\% of the sample) showed severe anxiety in speech-related situations, including telephone situations, and mild-to-moderate levels of the fear/anxiety total score. It might suggest that about $30 \%$ of treatment-seeking AWS have severe speech-related social anxiety. This subtype also showed high S-24 score. They may suffer from a wide range of speech-related difficulties.

Class 4 (15.9\% of the sample) reported moderate levels of speech-related anxiety and subclinical to mild levels of overall severity of social anxiety. They reported relatively higher public speaking anxiety, consistent with the characteristics of social anxiety in general population (e.g., Furmark et al., 1999).

Finally, class 5 (12.7\% of the sample) had severe social anxiety across the situations, except for observation or non-speech situations. This subtype was also characterized by high rate of unemployment and worsened communication attitude; they can show poor social functioning.

\subsection{Clinical considerations of telephone-specific social anxiety}

Previous studies have not assessed anxiety in telephone situations separately from the overall severity of social anxiety through the LSAS in AWS (e.g., Kakamad, 2021; McAllister et al., 2017). However, it is possible that focusing only on the overall severity of social anxiety can 
overlook clinically significant distress in telephone situations in some AWS, potentially

corresponding to class 2 in the present study. Adopting a bi-dimensional perspective would be clinically necessary to identify telephone-specific social anxiety in AWS.

In the current diagnostic criteria of SAD in the DSM-5 (American Psychiatric Association, 2013), individuals can be diagnosed with SAD if they feel fearful in one or more social situations. This criterion could lead to the same diagnosis of SAD in individuals who report anxiety in a wide range of social situations (potentially corresponding to classes 3 and 5 in the present study) and those only in telephone situations (potentially corresponding to class 2). However, different treatment packages can be necessary because telephone situations can be qualitatively different from other social situations due to the factors discussed above (James et al., 1999).

Several treatment approaches, including cognitive behavioral therapy (CBT; Menzies et al., 2008; Menzies et al., 2009), avoidance reduction therapy for stuttering (Sheehan \& Sisskin, 2001; Sisskin, 2018), and visual attention bias modification program (McAllister et al., 2017), have been applied to treat social anxiety in AWS. These approaches can include treatment strategies that utilize visual information, including keeping eye contact, visually processing social situations and other's behaviors and reactions, and visual disengagement from social threats. However, it may be possible that these interventions would be less effective for telephone-specific social anxiety, which may not depend on visual information. Future studies should consider an efficient treatment approach to treat telephone-specific social anxiety. 


\subsection{Limitations and future directions}

First, the LSAS measures anxiety in social situations that can be feared in general, and not feared specifically in AWS. The subtypes depend on indicators; therefore, using other scales that focus on situations that can be feared specifically in AWS, including the Speech Situation Checklist (Vanryckeghem et al., 2017), may reveal other subtypes.

Second, we focused on only situational factors influencing social anxiety and did not consider other factors that could potentially influence heterogeneity in the present study. While SAD is characterized by low novelty seeking and high behavioral inhibition as a whole (Kampman et al., 2014), recent studies have reported that there are distinct subtypes of SAD (Binelli et al., 2015; Kashdan \& Hofmann, 2008; Tillfors et al., 2013) showing high novelty seeking, a temperament that often accompanies exploratory pursuit behaviors in response to new interests or activities (Cloninger, 1987) and impulsivity. High impulsivity and novelty-seeking can be core dimensions of attentiondeficit hyperactivity disorder (ADHD) (Donfrancesco et al., 2015) and ADHD is related not only to social anxiety (Gorlin et al., 2016; Koyuncu et al., 2019; Yoshizawa et al., 2021), but also stuttering (Ajdacic-Gross et al., 2018; Alm, 2014; Druker et al., 2019). It would also be valuable to investigate whether factors other than social situations, including temperament and comorbidity, can lead to distinct subtypes of AWS in terms of social anxiety.

\section{Conclusion}

Social anxiety, measured through the LSAS, led to the five latent subtypes of AWS. These 
subtypes were related to psychosocial factors including employment status and communication

attitude. About one-quarter of the AWS were included in a subtype characterized by severe anxiety specific to telephone situations and they had sub-clinical level of overall severity of social anxiety. Telephone-specific subtype of social anxiety may be uniquely extracted in AWS. 


\section{References}

Aderka, I. M., Nickerson, A., \& Hofmann, S. G. (2012). Admixture analysis of the diagnostic subtypes of social anxiety disorder: Implications for the DSM-V. Journal of Behavior Therapy and Experimental Psychiatry, 43(2), 752-757. https://doi.org/10.1016/j.jbtep.2011.10.012

Ajdacic-Gross, V., Bechtiger, L., Rodgers, S., Müller, M., Kawohl, W., von Känel, R., Mutsch, M., Rössler, W., Seifritz, E., Castelao, E., Strippoli, M.-P. F., Vandeleur, C., Preisig, M., \& Howell, P. (2018). Subtypes of stuttering determined by latent class analysis in two Swiss $\begin{array}{llll}\text { epidemiological } & \text { surveys. } & \text { One, } & \text { 13(8), }\end{array}$ https://doi.org/10.1371/journal.pone.0198450

Alm, P. A. (2014). Stuttering in relation to anxiety, temperament, and personality: Review and analysis with focus on causality. Journal of Fluency Disorders, 40, 5-21. https://doi.org/10.1016/j.jfludis.2014.01.004

American Psychiatric Association. (1994). Diagnostic and statistical manual of mental disorders $\left(4^{\text {th }}\right.$ ed.).

American Psychiatric Association. (2000). Diagnostic and statistical manual of mental disorders-IVTR.

American Psychiatric Association. (2013). Diagnostic and statistical manual of mental disorders $\left(5^{\text {th }}\right.$ ed.). https://doi.org/10.1176/appi.books.9780890425596

Andrews, G., \& Cutler, J. (1974). Stuttering therapy: The relation between changes in symptom level 
and attitudes. Journal of Speech and Hearing Disorders, 39(3), 312-319. https://doi.org/10.1044/jshd.3903.312

Asakura, S., Inoue, S., Sasaki, F., Sasaki, Y., Kitagawa, N., Inoue, T., Denda, K., Ito, M., Matsubara, R., \& Koyama, T. (2002). Liebowitz Social Anxiety Scale nihongo ban no shinraisei oyobi datousei no kentou [Reliability and validity of the Japanese version of the Liebowitz Social Anxiety Scale]. Japan Journal of Clinical Psychiatry, 44(10), 1077-1084.

Binelli, C., Muñiz, A., Sanches, S., Ortiz, A., Navines, R., Egmond, E., Udina, M., Batalla, A., LópezSola, C., Crippa, J. A., Subirà, S., \& Martín-Santos, R. (2015). New evidence of heterogeneity in social anxiety disorder: Defining two qualitatively different personality profiles taking into account clinical, environmental and genetic factors. European Psychiatry, 30(1), 160-165. https://doi.org/10.1016/j.eurpsy.2014.09.418

Blood, G. W., \& Blood, I. M. (2004). Bullying in adolescents who stutter: Communicative competence and self-esteem. Contemporary Issues in Communication Science and Disorders, 31(31), 6979. https://doi.org/10.1044/cicsd_31_s_69

Blood, G. W., \& Blood, I. M. (2007). Preliminary study of self-reported experience of physical aggression and bullying of boys who stutter: Relation to increased anxiety. Perceptual and Motor Skills, 104(3 Pt 2), 1060-1066. https://doi.org/10.2466/pms.104.4.1060-1066

Blood, G. W., \& Blood, I. M. (2016). Long-term consequences of childhood bullying in adults who stutter: Social anxiety, fear of negative evaluation, self-esteem, and satisfaction with life. 
Journal of Fluency Disorders, 50, 72-84. https://doi.org/10.1016/j.jfludis.2016.10.002

Boyers, G. B., Broman-Fulks, J. J., Valentiner, D. P., McCraw, K., Curtin, L., \& Michael, K. D. (2017). The latent structure of social anxiety disorder and the performance only specifier: A taxometric $\begin{array}{llll}\text { analysis. } & \text { Cognitive } & \text { Behaviour } & \text { Therapy, }\end{array}$ https://doi.org/10.1080/16506073.2017.1338310

Bozdogan, H. (1987). Model selection and Akaike's Information Criterion (AIC): The general theory and its analytical extensions. Psychometrika, 52(3), 345-370. https://doi.org/10.1007/BF02294361

Chu, S. Y., Sakai, N., Lee, J., Harrison, E., Tang, K. P., \& Mori, K. (2020). Comparison of social anxiety between Japanese adults who stutter and non-stuttering controls. Journal of Fluency Disorders, 105767. https://doi.org/10.1016/j.jfludis.2020.105767

Clark, S. L., \& Muthén, B. O. (2013). Relating latent class analysis results to variables not included in the analysis. Unpublished manuscript.

Cloninger, C. R. (1987). A systematic method for clinical description and classification of personality variants. A proposal. Archives of General Psychiatry, 44(6), 573-588. https://doi.org/10.1001/archpsyc.1987.01800180093014

Cox, B. J., Clara, I. P., Sareen, J., \& Stein, M. B. (2008). The structure of feared social situations among individuals with a lifetime diagnosis of social anxiety disorder in two independent nationally representative mental health surveys. Behaviour Research and Therapy, 46(4), 477-486. 


\section{https://doi.org/10.1016/j.brat.2008.01.011}

Craig, A., \& Tran, Y. (2014). Trait and social anxiety in adults with chronic stuttering: Conclusions following meta-analysis. Journal of Fluency Disorders, 40, 35-43. https://doi.org/10.1016/j.jfludis.2014.01.001

Crome, E., \& Baillie, A. (2014). Mild to severe social fears: Ranking types of feared social situations using item response theory. Journal of Anxiety Disorders, 28(5), 471-479. https://doi.org/10.1016/j.janxdis.2014.05.002

Crome, E., Grove, R., Baillie, A. J., Sunderland, M., Teesson, M., \& Slade, T. (2015). DSM-IV and DSM-5 social anxiety disorder in the Australian community. Australian and New Zealand Journal of Psychiatry, 49(3), 227-235. https://doi.org/10.1177/0004867414546699

Diehl, J., Robb, M. P., Lewis, J. G., \& Ormond, T. (2018). Situational speaking anxiety in adults who stutter. Speech, Language and Hearing, 22(2), 100-110. https://doi.org/10.1080/2050571x.2018.1441782

Donfrancesco, R., Di Trani, M., Porfirio, M. C., Giana, G., Miano, S., \& Andriola, E. (2015). Might the temperament be a bias in clinical study on attention-deficit hyperactivity disorder (ADHD)?: Novelty Seeking dimension as a core feature of ADHD. Psychiatry Research, 227(2), 333-338. https://doi.org/10.1016/i.psychres.2015.02.014

Druker, K., Hennessey, N., Mazzucchelli, T., \& Beilby, J. (2019). Elevated attention deficit hyperactivity disorder symptoms in children who stutter. Journal of Fluency Disorders, 59, 80- 


\section{0. https://doi.org/10.1016/j.jfludis.2018.11.002}

Enders, C. K. (2010). Applied missing data analysis. Guilford press.

Ezrati-Vinacour, R., \& Levin, I. (2004). The relationship between anxiety and stuttering: A multidimensional approach. Journal of Fluency Disorders, 29(2), 135-148. https://doi.org/10.1016/j.jfludis.2004.02.003

Fuentes-Rodriguez, G., Garcia-Lopez, L. J., \& Garcia-Trujillo, V. (2018). Exploring the role of the DSM-5 performance-only specifier in adolescents with social anxiety disorder. Psychiatry Research, 270, 1033-1038. https://doi.org/10.1016/j.psychres.2018.03.052

Furmark, T., Tillfors, M., Everz, P., Marteinsdottir, I., Gefvert, O., \& Fredrikson, M. (1999). Social phobia in the general population: Prevalence and sociodemographic profile. Social Psychiatry and Psychiatric Epidemiology, 34(8), 416-424. https://doi.org/10.1007/s001270050163

Gomez, R., \& Watson, S. D. (2017). Confirmatory factor analysis of the combined Social Phobia Scale and Social Interaction Anxiety Scale: Support for a bifactor model. Frontiers in Psychology, 8,

\section{0. https://doi.org/10.3389/fpsyg.2017.00070}

Gorlin, E. I., Dalrymple, K., Chelminski, I., \& Zimmerman, M. (2016). Diagnostic profiles of adult psychiatric outpatients with and without attention deficit hyperactivity disorder. Comprehensive Psychiatry, 70, 90-97. https://doi.org/10.1016/j.comppsych.2016.06.015

Haitani, T., Sakai, N., Mori, K., \& Houjou, T. (Submitted manuscript). Situational factors influencing social anxiety among treatment-seeking adults who stutter: An exploratory factor analysis. 


\section{Submitted manuscript.}

Hallquist, M. N., \& Wiley, J. F. (2018). MplusAutomation: An R package for facilitating large-scale latent variable analyses in Mplus. Structural Equation Modeling: A Multidisciplinary Journal, 25(4), 621-638. https://doi.org/10.1080/10705511.2017.1402334

Iverach, L., O'Brian, S., Jones, M., Block, S., Lincoln, M., Harrison, E., Hewat, S., Menzies, R. G., Packman, A., \& Onslow, M. (2009). Prevalence of anxiety disorders among adults seeking speech therapy for stuttering. Journal of Anxiety Disorders, 23(7), 928-934. https://doi.org/10.1016/j.janxdis.2009.06.003

Iverach, L., \& Rapee, R. M. (2014). Social anxiety disorder and stuttering: Current status and future $\begin{array}{llll}\text { directions. } \quad \text { Journal } & \text { Fluency } & \text { Disorders, } & \text { 40, }\end{array}$ https://doi.org/10.1016/j.jfludis.2013.08.003

James, S. E., Brumfitt, S., \& Cowell, P. (2009). The influence of communication situation on selfreport in people who stutter. International Journal of Speech-Language Pathology, 11(1), 34-

\section{4. https://doi.org/10.1080/17549500802588179}

James, S. E., Brumfitt, S. M., \& Cudd, P. A. (1999). Communicating by telephone: Views of a group of people with stuttering impairment. Journal of Fluency Disorders, 24(4), 299-317. https://doi.org/10.1016/S0094-730X(99)00019-4

Kakamad, K. K. (2021). The effect of cognitive behavioral therapy in reducing social anxiety among adult stutters. Technium Social Sciences Journal, 20(1), 540-545. 


\section{https://techniumscience.com/index.php/socialsciences/article/view/3415}

Kampman, O., Viikki, M., Järventausta, K., \& Leinonen, E. (2014). Meta-analysis of anxiety disorders and temperament. Neuropsychobiology, 69(3), 175-186. https://doi.org/10.1159/000360738

Kashdan, T. B., \& Hofmann, S. G. (2008). The high-novelty-seeking, impulsive subtype of generalized social anxiety disorder. Depression and Anxiety, 25(6), 535-541. https://doi.org/10.1002/da.20382

Klompas, M., \& Ross, E. (2004). Life experiences of people who stutter, and the perceived impact of stuttering on quality of life: Personal accounts of South African individuals. Journal of Fluency Disorders, 29(4), 275-305. https://doi.org/10.1016/j.jfludis.2004.10.001

Knappe, S., Beesdo-Baum, K., Fehm, L., Stein, M. B., Lieb, R., \& Wittchen, H. U. (2011). Social fear and social phobia types among community youth: Differential clinical features and vulnerability factors. Journal of Psychiatric Research, 45(1), 111-120. https://doi.org/10.1016/j.jpsychires.2010.05.002

Kollman, D. M., Brown, T. A., Liverant, G. I., \& Hofmann, S. G. (2006). A taxometric investigation of the latent structure of social anxiety disorder in outpatients with anxiety and mood disorders. Depression and Anxiety, 23(4), 190-199. https://doi.org/10.1002/da.20158

Koyuncu, A., Çelebi, F., Ertekin, E., Kök, B. E., \& Tükel, R. (2019). Clinical effects of ADHD subtypes in patients with social anxiety disorder. Journal of Attention Disorders, 23(12), 1464-1469. https://doi.org/10.1177/1087054715617533 
Langevin, M., Packman, A., \& Onslow, M. (2009). Peer responses to stuttering in the preschool setting. American Journal of Speech-Language Pathology, 18(3), 264-276.

\section{https://doi.org/10.1044/1058-0360(2009/07-0087)}

Lo, Y., Mendell, N. R., \& Rubin, D. B. (2001). Testing the number of components in a normal mixture. Biometrika, 88(3), 767-778. https://doi.org/10.1093/biomet/88.3.767

Masyn, K. E. (2013). Latent class analysis and finite mixture modeling. In T. D. Little (Ed.), The Oxford handbook of quantitative methods: Vol. 2. Statistical analysis (pp. 551-611). Oxford University Press. https://doi.org/10.1093/oxfordhb/9780199934898.013.0025

McAllister, J., Gascoine, S., Carroll, A., Humby, K., Kingston, M., Shepstone, L., Risebro, H., Mackintosh, B., Thompson, T. D., \& Hodgekins, J. (2017). Cognitive bias modification for social anxiety in adults who stutter: A feasibility study of a randomised controlled trial. $B M J$ Open, 7(10), e015601. https://doi.org/10.1136/bmjopen-2016-015601

Menzies, R. G., O’Brian, S., Onslow, M., Packman, A., St Clare, T., \& Block, S. (2008). An experimental clinical trial of a cognitive-behavior therapy package for chronic stuttering. Journal of Speech, Language, and Hearing Research, 51(6), 1451-1464. https://doi.org/10.1044/1092-4388(2008/07-0070)

Menzies, R. G., Onslow, M., \& Packman, A. (1999). Anxiety and stuttering: Exploring a complex relationship. American Journal of Speech-Language Pathology, 8(1), 3-10. https://doi.org/10.1044/1058-0360.0801.03 
Menzies, R. G., Onslow, M., Packman, A., \& O'Brian, S. (2009). Cognitive behavior therapy for adults who stutter: A tutorial for speech-language pathologists. Journal of Fluency Disorders, 34(3), 187-200. https://doi.org/10.1016/j.jfludis.2009.09.002

Messenger, M., Onslow, M., Packman, A., \& Menzies, R. (2004). Social anxiety in stuttering: Measuring negative social expectancies. Journal of Fluency Disorders, 29(3), 201-212. https://doi.org/10.1016/j.jfludis.2004.06.002

Morgan, G. B., Hodge, K. J., \& Baggett, A. R. (2016). Latent profile analysis with nonnormal mixtures: A Monte Carlo examination of model selection using fit indices. Computational Statistics \& Data Analysis, 93, 146-161. https://doi.org/10.1016/j.csda.2015.02.019

Morin, A. J. S., \& Marsh, H. W. (2015). Disentangling shape from level effects in person-centered analyses: An illustration based on university teachers' multidimensional profiles of effectiveness. Structural Equation Modeling: A Multidisciplinary Journal, 22(1), 39-59. https://doi.org/10.1080/10705511.2014.919825

Muthén, L. K., \& Muthén, B. O. (1998-2017). Mplus User ’s Guide. Eighth Edition. Muthén \& Muthén. Nandi, A., Beard, J. R., \& Galea, S. (2009). Epidemiologic heterogeneity of common mood and anxiety disorders over the lifecourse in the general population: A systematic review. BMC Psychiatry, 9(1), 31. https://doi.org/10.1186/1471-244X-9-31

Nylund-Gibson, K., \& Choi, A. Y. (2018). Ten frequently asked questions about latent class analysis. Translational Issues in Psychological Science, 4(4), 440-461. 


\section{https://doi.org/10.1037/tps0000176}

Oakman, J., Van Ameringen, M., Mancini, C., \& Farvolden, P. (2003). A confirmatory factor analysis of a self-report version of the Liebowitz Social Anxiety Scale. Journal of Clinical Psychology, 59(1), 149-161. https://doi.org/10.1002/jclp.10124

Pastor, D. A., Barron, K. E., Miller, B. J., \& Davis, S. L. (2007). A latent profile analysis of college students' achievement goal orientation. Contemporary Educational Psychology, 32(1), 8-47. https://doi.org/10.1016/j.cedpsych.2006.10.003

Peyre, H., Hoertel, N., Rivollier, F., Landman, B., McMahon, K., Chevance, A., Lemogne, C., Delorme, R., Blanco, C., \& Limosin, F. (2016). Latent class analysis of the feared situations of social anxiety disorder: A population-based study. Depression and Anxiety, 33(12), 1178-1187. https://doi.org/10.1002/da.22547

Revelle, W. (2018). psych: Procedures for personality and psychological research, Northwestern University, Evanston, Illinois, USA, Version $=1.8 .3$. https://CRAN.Rproject.org/package $=$ psych

Ruscio, A. M. (2010). The latent structure of social anxiety disorder: Consequences of shifting to a dimensional diagnosis. Journal of Abnormal Psychology, 119(4), 662-671. https://doi.org/10.1037/a0019341

Ruscio, A. M., Brown, T. A., Chiu, W. T., Sareen, J., Stein, M. B., \& Kessler, R. C. (2008). Social fears and social phobia in the USA: Results from the National Comorbidity Survey Replication. 
Psychological Medicine, 38(1), 15-28. https://doi.org/10.1017/s0033291707001699

Safren, S. A., Heimberg, R. G., Horner, K. J., Juster, H. R., Schneier, F. R., \& Liebowitz, M. R. (1999). Factor structure of social fears: The Liebowitz Social Anxiety Scale. Journal of Anxiety Disorders, 13(3), 253-270. https://doi.org/10.1016/s0887-6185(99)00003-1

Sakai, N., Chu, S. Y., Mori, K., Mochida, A., Houjou, T., \& Sakata, Y. (2014). Communication attitudes of adults who stutter: The modifeid Erickson communication attitudes scale (S-24). Proceedings of the 15th meeting of Japanese association of speech-language-hearing therapists, 15, 172.

Sakai, N., Chu, S. Y., Mori, K., \& Yaruss, J. S. (2017). The Japanese version of the overall assessment of the speaker's experience of stuttering for adults (OASES-AJ): Translation and psychometric evaluation. Journal of Fluency Disorders, 51, 50-59. https://doi.org/10.1016/j.jfludis.2016.11.002

Salzer, S., Pincus, A. L., Hoyer, J., Kreische, R., Leichsenring, F., \& Leibing, E. (2008). Interpersonal subtypes within generalized anxiety disorder. Journal of Personality Assessment, 90(3), 292299. https://doi.org/10.1080/00223890701885076

Sawilowsky, S. S. (2009). New effect size rules of thumb. Journal of Modern Applied Statistical Methods, 8(2), 26. https://doi.org/10.22237/jmasm/1257035100

Schwarz, G. (1978). Estimating the dimension of a model. Annals of Statistics, 6(2), 461-464. https://doi.org/10.1214/aos/1176344136 
Sheehan, V. M., \& Sisskin, V. (2001). The creative process in Avoidance Reduction Therapy for Stuttering. Perspectives on Fluency and Fluency Disorders, 11(1), 7-11.

\section{https://doi.org/10.1044/ffd11.1.7}

Sisskin, V. (2018). Avoidance Reduction Therapy for Stuttering (ARTS®). In Barbara J. Amster \& E.

R. Klein (Eds.), More Than Fluency: The Social, Emotional, and Cognitive Dimensions of Stuttering. Plural Publishing Inc.

Stein, D. J., Kasper, S., Andersen, E. W., Nil, R., \& Lader, M. (2004). Escitalopram in the treatment of social anxiety disorder: Analysis of efficacy for different clinical subgroups and symptom dimensions. Depression and Anxiety, 20(4), 175-181. https://doi.org/10.1002/da.20043

Stein, D. J., Ruscio, A. M., Lee, S., Petukhova, M., Alonso, J., Andrade, L. H. S. G., Benjet, C., Bromet, E., Demyttenaere, K., Florescu, S., de Girolamo, G., de Graaf, R., Gureje, O., He, Y., Hinkov, H., Hu, C., Iwata, N., Karam, E. G., Lepine, J.-P., Matschinger, H., Oakley Browne, M., Posada-Villa, J., Sagar, R., Williams, D. R., \& Kessler, R. C. (2010). Subtyping social anxiety disorder in developed and developing countries. Depression and Anxiety, 27(4), 390-403. https://doi.org/10.1002/da.20639

Stein, M. B., Baird, A., \& Walker, J. R. (1996). Social phobia in adults with stuttering. American Journal of Psychiatry, 153(2), 278-280. https://doi.org/10.1176/ajp.153.2.278

Stein, M. B., Torgrud, L. J., \& Walker, J. R. (2000). Social phobia symptoms, subtypes, and severity: Findings from a community survey. Archives of General Psychiatry, 57(11), 1046-1052. 


\section{https://doi.org/10.1001/archpsyc.57.11.1046}

Stemberger, R. T., Turner, S. M., Beidel, D. C., \& Calhoun, K. S. (1995). Social phobia: An analysis of possible developmental factors. Journal of Abnormal Psychology, 104(3), 526-531. https://doi.org/10.1037//0021-843x.104.3.526

submitted companion manuscript. Situational factors influencing social anxiety in treatment-seeking adults who stutter: Factor analyses.

Tein, J. Y., Coxe, S., \& Cham, H. (2013). Statistical power to detect the correct number of classes in latent profile analysis. Structural Equation Modeling, 20(4), 640-657. https://doi.org/10.1080/10705511.2013.824781

Tillfors, M., Van Zalk, N., \& Kerr, M. (2013). Investigating a socially anxious-impulsive subgroup of adolescents: A prospective community study. Scandinavian Journal of Psychology, 54(3), 267273. https://doi.org/10.1111/sjop.12047

Vanryckeghem, M., Matthews, M., \& Xu, P. (2017). Speech Situation Checklist-Revised: Investigation with adults who do not stutter and treatment-seeking adults who stutter. American Journal of Speech-Language Pathology, 26(4), 1129-1140. https://doi.org/10.1044/2017 AJSLP-16-0170

Vermunt, J. K., \& Magidson, J. (2002). Latent class cluster analysis. In A. L. McCutcheon \& J. A. Hagenaars (Eds.), Applied latent class analysis (pp. 89-106). Cambridge University Press. https://doi.org/10.1017/CBO9780511499531.004

Vriends, N., Becker, E. S., Meyer, A., Michael, T., \& Margraf, J. (2007). Subtypes of social phobia: 
Are they of any use? Journal of Anxiety Disorders, 21(1), 59-75. https://doi.org/10.1016/j.janxdis.2006.05.002

Wang, M.-C., Deng, Q., Bi, X., Ye, H., \& Yang, W. (2017). Performance of the entropy as an index of classification accuracy in latent profile analysis: A Monte Carlo simulation study. Acta Psychologica Sinica, 49(11), 1473-1482. https://doi.org/10.3724/sp.J.1041.2017.01473

Yoshizawa, K., Ishizuka, I., Yasuda, N., Fukuda, M., Yukimoto, Y., Hata, W., Higashikawa, M., \& Hara, Y. (2021). Seijin kitsuonsha no jihei supekutoramu keikou oyobi chuui ketsujyo tadoushou keikou to shakou huan tono kanren [The relationship between autism spectrum disorder tendency or attention deficit hyperactivity disorder tendency and social anxiety in adult patients with stuttering]. Onsei Gengo Igaku, 62(1), 24-32.

[dataset] Response data of the Liebowitz social anxiety scale among Japanese treatment-seeking adults who stutter. Mandeley data, 2021. (Auhtor names are blind in the review process) 
Table 1

\begin{tabular}{ll}
\hline & \\
\hline Age & $n$ (percentage) \\
10 's & $43(7.7 \%)$ \\
20 's & $314(56.0 \%)$ \\
30 's & $121(21.6 \%)$ \\
40 's & $65(11.6 \%)$ \\
50 's & $14(2.5 \%)$ \\
60 's & $4(0.7 \%)$ \\
Gender & \\
Women & $117(20.9 \%)$ \\
Men & $444(79.1 \%)$ \\
Onset of stuttering & \\
Under 10 years old & $346(61.7 \%)$ \\
10 's & $139(24.8 \%)$ \\
20's & $43(7.7 \%)$ \\
30's & $10(1.8 \%)$ \\
40 's & $2(0.4 \%)$ \\
50's & $2(0.4 \%)$ \\
Unclear & $19(3.4 \%)$ \\
Employment status & \\
Employed & $304(54.2 \%)$ \\
Unemployed & $75(13.4 \%)$ \\
Student & $151(26.9 \%)$ \\
Unclear & $31(5.5 \%)$ \\
\hline
\end{tabular}


Table 2

Fit indices for the competing latent class models

\begin{tabular}{|c|c|c|c|c|c|c|c|c|}
\hline & \multicolumn{8}{|c|}{ Number of classes } \\
\hline & 1 & 2 & 3 & 4 & 5 & 6 & 7 & 8 \\
\hline Free parameters & 10 & 16 & 22 & 28 & 34 & 40 & 46 & 52 \\
\hline Log-likelihood & -3297.68 & -2872.22 & -2758.73 & -2684.75 & -2654.16 & -2634.82 & -2601.05 & -2585.28 \\
\hline $\begin{array}{l}P \text {-value of Lo-Mendell-Rubin adjusted likelihood ratio } \\
\text { test (LMR-aLRT) }{ }^{\text {a }}\end{array}$ & - & $<.001$ & $<.001$ & $<.001$ & .10 & .25 & $<.001$ & .88 \\
\hline Bayes information criteria (BIC) & 6658.65 & 5845.71 & 5656.71 & 5546.73 & 5523.53 & 5522.84 & 5493.28 & 5499.7 \\
\hline Consistent Akaike information criteria (CAIC) & 6668.65 & 5861.71 & 5678.71 & 5574.72 & 5557.53 & 5562.84 & 5539.28 & 5551.7 \\
\hline Integrated classification likelihood BIC (ICL-BIC) & - & 5847.42 & 5658.36 & 5548.33 & 5525.11 & 5524.43 & 5494.89 & 5501.27 \\
\hline Entropy statistic & - & .85 & .82 & .80 & .79 & .80 & .80 & .79 \\
\hline $\begin{array}{l}\text { Minimum proportion of individuals belonging to } \\
\text { classes }\end{array}$ & - & .44 & .13 & .12 & .13 & .05 & .06 & .05 \\
\hline
\end{tabular}

Note. Significant $p$-values, minimum values of the information criteria, and maximum values of the entropy statistic are in bold.

${ }^{a}$ LMR-aLRT compares the model fits of the $k$ classes with those of the neighbor $(k-1)$ classes. 


\section{Table 3}

Demographic information and overall social anxiety levels in the identified five classes of adults who stutter

\begin{tabular}{|c|c|c|c|c|c|c|c|c|c|c|c|c|c|}
\hline \multirow[t]{2}{*}{ Class } & \multicolumn{2}{|c|}{$\begin{array}{c}\text { Gender } \\
n \text { (percentage) }\end{array}$} & \multicolumn{2}{|c|}{ Age } & \multicolumn{4}{|c|}{$\begin{array}{c}\text { Employment status } \\
n \text { (percentage) }\end{array}$} & \multicolumn{2}{|c|}{$\mathrm{S}-24^{\mathrm{a}}$} & \multicolumn{2}{|c|}{$\begin{array}{l}\text { Fear/anxiety } \\
\text { total score }^{\mathrm{b}}\end{array}$} & \multirow[t]{2}{*}{$\begin{array}{c}\text { Social anxiety } \\
\text { severity }^{c}\end{array}$} \\
\hline & Women & Men & $M$ & $S D$ & Employed & Student & Unemployed & Unclear & $M$ & $S D$ & $M$ & $S D$ & \\
\hline Class 1 & $\begin{array}{c}13 \\
(15 \%)\end{array}$ & $\begin{array}{c}72 \\
(85 \%)\end{array}$ & 31.0 & 10.2 & $\begin{array}{c}51 \\
(60 \%)\end{array}$ & $\begin{array}{c}23 \\
(27 \%)\end{array}$ & $\begin{array}{c}6 \\
(7 \%)\end{array}$ & $\begin{array}{c}5 \\
(6 \%)\end{array}$ & 13.86 & 4.19 & 10.79 & 5.58 & Sub-clinical \\
\hline Class 2 & $\begin{array}{c}34 \\
(22 \%)\end{array}$ & $\begin{array}{c}122 \\
(78 \%)\end{array}$ & 27.5 & 7.3 & $\begin{array}{c}92 \\
(59 \%)\end{array}$ & $\begin{array}{c}41 \\
(26 \%)\end{array}$ & $\begin{array}{c}13 \\
(8 \%)\end{array}$ & $\begin{array}{c}10 \\
(6 \%)\end{array}$ & 16.93 & 4.42 & 21.85 & 6.59 & Sub-clinical \\
\hline Class 3 & $\begin{array}{c}43 \\
(27 \%)\end{array}$ & $\begin{array}{c}117 \\
(73 \%)\end{array}$ & 27.6 & 8.4 & $\begin{array}{c}80 \\
(50 \%)\end{array}$ & $\begin{array}{c}53 \\
(33 \%)\end{array}$ & $\begin{array}{c}22 \\
(14 \%)\end{array}$ & $\begin{array}{c}5 \\
(3 \%)\end{array}$ & 20.51 & 2.53 & 39.93 & 6.85 & Mild to moderate \\
\hline Class 4 & $\begin{array}{c}11 \\
(12 \%)\end{array}$ & $\begin{array}{c}78 \\
(88 \%)\end{array}$ & 30.8 & 10.2 & $\begin{array}{c}50 \\
(56 \%)\end{array}$ & $\begin{array}{c}18 \\
(20 \%)\end{array}$ & $\begin{array}{c}16 \\
(18 \%)\end{array}$ & $\begin{array}{c}5 \\
(6 \%)\end{array}$ & 17.51 & 3.64 & 28.05 & 6.51 & $\begin{array}{l}\text { Sub-clinical to } \\
\text { mild }\end{array}$ \\
\hline Class 5 & $\begin{array}{c}16 \\
(23 \%)\end{array}$ & $\begin{array}{c}55 \\
(77 \%)\end{array}$ & 30.9 & 10.0 & $\begin{array}{c}31 \\
(44 \%)\end{array}$ & $\begin{array}{c}16 \\
(23 \%)\end{array}$ & $\begin{array}{c}18 \\
(25 \%)\end{array}$ & $\begin{array}{c}6 \\
(8 \%)\end{array}$ & 21.73 & 1.87 & 54.74 & 7.52 & Severe \\
\hline
\end{tabular}

${ }^{\text {a }}$ All the available data was used.

$\mathrm{b}$ Total scores were calculated through available items.

${ }^{\mathrm{c}}$ Severity rating is based on the mean fear/anxiety total scores of the subtypes, referring to severity ratings reported in Asakura et al. (2002). 


\section{Figure 1}

Profiles of social anxiety in the identified five classes of adults who stutter

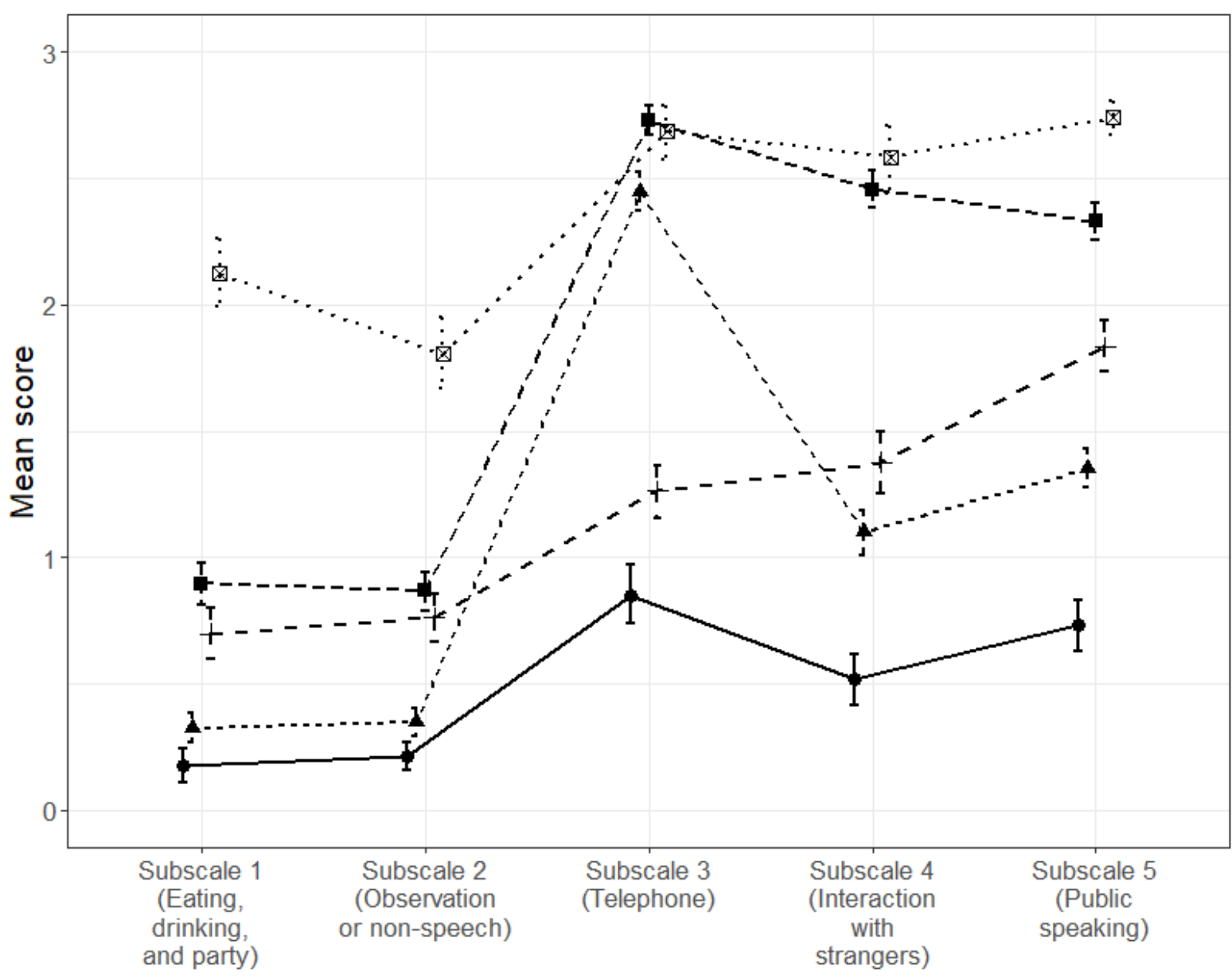

Class 1:

Mild social anxiety across social situations $(n=85 ; 15.2 \%)$

A. Severe social anxiety in telephone situations $(n=156 ; 27.8 \%)$

Class 3:

- Severe social anxiety in speech-related situations $(n=160 ; 28.5 \%)$

- Moderate social anxiety in speech-related situations $(n=89 ; 15.9 \%)$

$$
\begin{aligned}
& (n=89 \\
& \text { Class } 5
\end{aligned}
$$

$\cdot \otimes \cdot$ Severe social anxiety across social situations $(n=71 ; 12.7 \%)$

Note. Error bars indicate bootstrapped 95\% confidence intervals. 